\title{
A Contribution To The Capability Of The Measuring Device USED In The Automotive
}

\author{
Katerina Bicova, Lubos Kroft \& Aneta Milsimerova
}
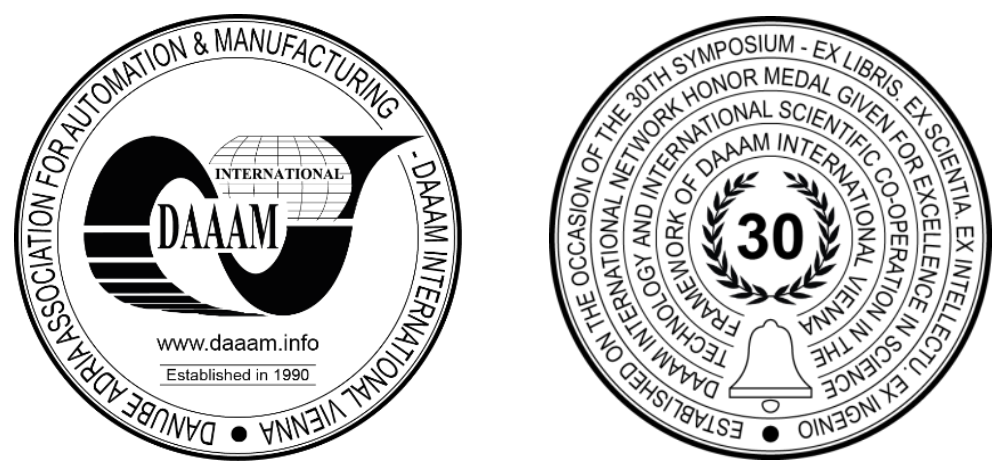

This Publication has to be referred as: Bicova, K[aterina]; Kroft, L[ubos] \& Milsimerova, A[neta] (2020). A Contribution to the Capability of the Measuring Device Used in the Automotive, Proceedings of the 31st DAAAM International Symposium, pp.0197-0201, B. Katalinic (Ed.), Published by DAAAM International, ISBN 978-3-90273429-7, ISSN 1726-9679, Vienna, Austria

DOI: $10.2507 / 31$ st.daaam.proceedings.026

\begin{abstract}
The automotive sector places high demands on the quality of products and services. The paper focuses on evaluating of the measuring equipment capability, which is used to verify the accuracy of parts for the automotive industry. It is mainly about verifying the suitability and ensuring relevant values for the subsequent verification of the production process capability. The requirements for the production accuracy and associated competence are required by the ISO 9000 series of standards, especially IATF 16949 for the automotive industry. The analysis was focused on the optical comparator Keyence IM-7000, which is used for control and rapid analysis with the minimization of the human factor. The capability of the measuring equipment was verified according to the methodology from Ford and Bosh.
\end{abstract}

Keywords: capability; capability of measuring equipment; ISO 9000; IATF 16949; automotive.

\section{Introduction}

The main idea of today's market is to speed up production processes and increase the quality of the products and services. Related to this is the effort to meet the customer requirements, which are constantly growing with the competitiveness and development of modern technologies. All these approaches seek to support the ISO 9000 series standards. ISO 9001 requirements focus on the product quality, maintaining the capability of the production process, high quality service and product delivery to customers. For the automotive sector, these requirements are extended by document IATF 16949, which is based on both the appropriate use of statistical methods and the maintenance of the competence of the production process. [1][2].

In this paper, we have focused on the capability, because process competence is an important aspect of the quality production. The main idea for the follow-up study is that appropriate and relevant data are needed to verify the capability of the process. In our case, a measuring equipment is used for data collection, for which it's the capability has been verified. [3][4]. The aim is therefore to verify the capability of the measuring equipment, to determine the width of the tolerance field, where given the measuring equipment meets the conditions for its capability. This will also ensure a minimal impact on the subsequent evaluation of the process capability, and the associated ability to offer customers a consistently high quality product at economically comparable costs. 


\section{The current approach to quality in the field of measurement}

In this article is describe not on the evaluation measuring system (MSA, VDA 5,...), but in this article, we focused on measuring the capability of measuring equipment according to the methodology of company Ford and company Bosh.[5][6]

Both these methods are based on the assumption that the suitability test is performed on a real product. In these methods, the real product fulfils the role of a standard. The real value of the standard (the real product) must be determined using measuring equipment that has the accuracy of two orders of magnitude higher than that used when manufacturing real product. The method then consists of repeatedly measuring the value of the standard. The detected variance is compared with a part of the tolerance field, usually $15 \%$ or $20 \%$ of the tolerance field. The procedure of using the method to evaluate the suitability of the measuring equipment is simple. It is performed by repeated measurements of a standard (real part) for which we know the nominal values. Measuring is performed by only one operator on the same measuring equipment which is being evaluated and one measured part. The measured values are then compared with a part of the tolerance field, usually with a proportion of $15 \%$ to $20 \%$ of the tolerance field.

The basic indicators of measuring equipment capability are the parameters cg and cgk. These indicate the value of repeatability (cg) and reproducibility (cgk) of the inspected measuring equipment. The method of calculating these parameters varies according to the methodology used (by company Ford, or by company Bosh). [6][7]

\subsection{Bosh}

Parameters that are used by the company Bosch are calculated as $20 \%$ of the width of the specification field. The required value of $\mathrm{Cg}$ and $\mathrm{Cgk}$ is compared with a value of 1.33 and more. The formulas for calculating the $\mathrm{Cg}$ index are as follows:

$$
\begin{array}{r}
c_{g}=\frac{0,2 s_{p}}{s_{g}} \\
c_{g}=\frac{0,2 T}{6 s_{g}}
\end{array}
$$

where the calculation is related to the width of the specification field T. In both cases, sp is the standard deviation of the process and sg is the standard deviation of the measured values.

The second eligibility indicator is Cgk. Cgk indicators can also be determined in various ways. A method related to process variance or specification field width is used. The relation to process variance is:

$$
c_{g k}=\min \left\{\frac{\left.\left(x_{r}+0,1 T\right)-\bar{x}\right)}{3 s_{g}} \mid \frac{\bar{x}-\left(x_{r}-0,1 T\right)}{3 s_{g}}\right\}
$$

When using the method for calculation according to the variance of the process, the relations are similar. Instead of the variable $\mathrm{T}$, the selection standard deviation of the process $6 \mathrm{sp}$ is used. The relation to the specification field width is:

$$
c_{g k}=\min \left\{\frac{\left.\left(x_{r}+0,1 \times 6 s_{p}\right)-\bar{x}\right)}{3 s_{g}} \mid \frac{\bar{x}-\left(x_{r}-0,1 \times 6 s_{p}\right)}{3 s_{g}}\right\}
$$

\subsection{Ford}

The variant according to Ford takes into account a bandwidth of $15 \%$. In this method of calculation, measuring devices are recognized as eligible if the values of $\mathrm{Cg}$ and $\mathrm{Cgk}$ are greater than 1 . The relationships for the calculation of the indicator $\mathrm{Cg}$ are as follows:

$$
\begin{array}{r}
c_{g}=\frac{0,15 s_{p}}{s_{g}} \\
c_{g}=\frac{0,15 T}{6 s_{g}}
\end{array}
$$

where the calculation is related to the width of the specification field T. In both cases, sp is the standard deviation of the process and sg is the standard deviation of the measured values.

To determine the indicator $\mathrm{Cgk}$, the relation related to the variance of the process is used: 


$$
c_{g k}=\min \left\{\frac{\left.\left(x_{r}+0,075 T\right)-\bar{x}\right)}{3 s_{g}} \mid \frac{\bar{x}-\left(x_{r}-0,075 T\right)}{3 s_{g}}\right\}
$$

The relationship related to the width of the specification field occurs after adjustment similarly to the Bosch variant:

$$
c_{g k}=\min \left\{\frac{\left.\left(x_{r}+0,075 \times 6 s_{p}\right)-\bar{x}\right)}{3 s_{g}} \mid \frac{\bar{x}-\left(x_{r}-0,075 \times 6 s_{p}\right)}{3 s_{g}}\right\}
$$

\section{Description of the measuring equipment and method of measurement}

The aim of the experiment was to verify the capability of the optical comparator Keyence IM-7000 (Fig.1). The optical comparator is used for control and fast analysis with minimization of the human factor. It works on the principle of digital photographing of the part and subsequent evaluation in the form of dimensions. The comparator consists of a main unit, which consists of an LCD monitor, USB ports, etc., as well as a camera with a lens and a table with a load capacity of up to $5 \mathrm{~kg}$.

The advantage of the comparator is the possibility of illuminating the sample at different angles and directions. Another advantage is the high depth of field, in the range of $+-10 \mathrm{~mm}$, thanks to which it is possible to obtain a sharp image even on complex samples. Possibility of measuring at least 80 parameters on each of the components at once and the possibility of measuring min. 25 identical components at once.

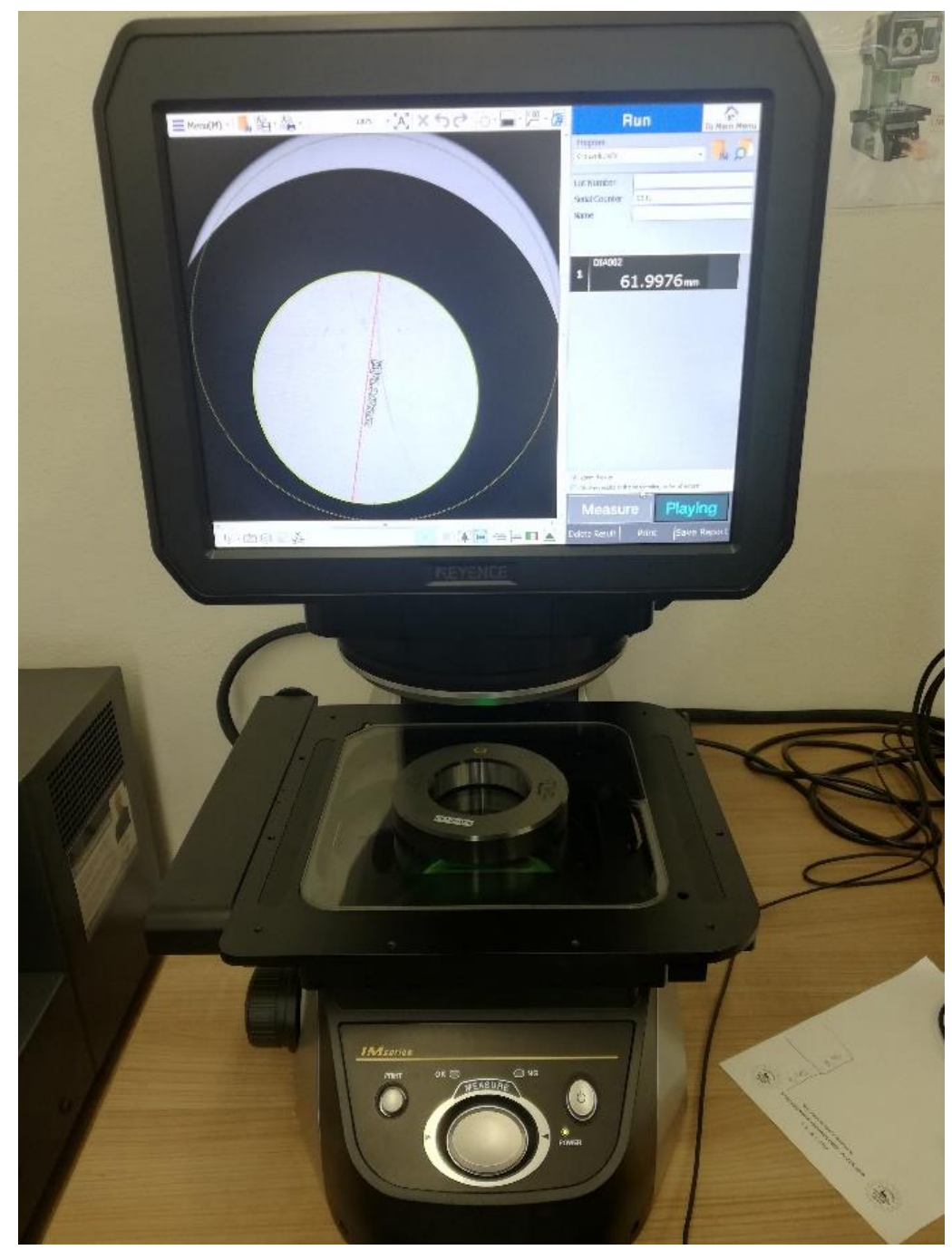

Fig. 1. Optical comparator Keyence IM-7000

Measurements were performed after 36 repetitions by one worker, under constant environmental conditions. The diameter of the calibration ring was evaluated (Fig. 2). The nominal size of the calibration ring is $61.997 \mathrm{~mm}$. 


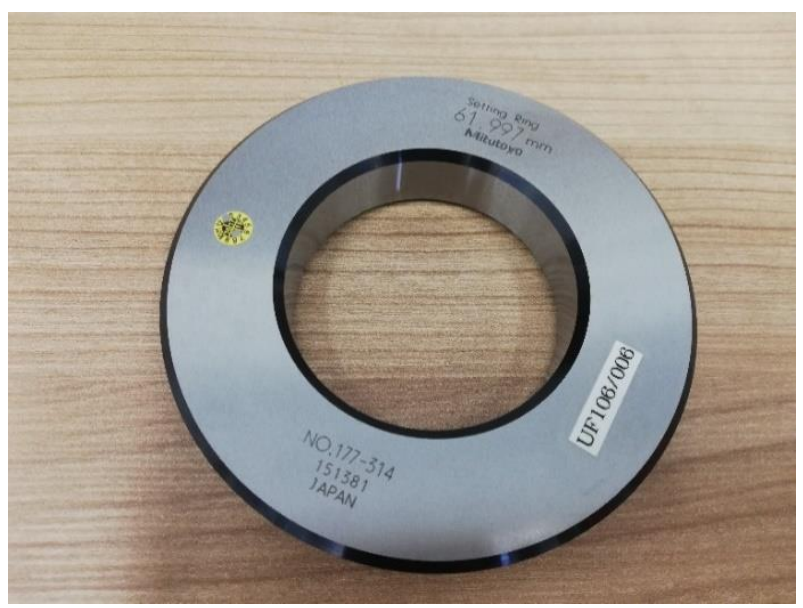

Fig. 2. The calibration ring

The following table (tab.1) show the measured values.

\begin{tabular}{|c|c|c|c|c|c|c|c|c|c|}
\hline Nr. & Actual $\varnothing$ & Nr. & Actual $\varnothing$ & Nr. & Actual $\varnothing$ & Nr. & Actual $\varnothing$ & Nr. & Actual $\varnothing$ \\
\hline $\mathbf{1}$ & 61,9960 & $\mathbf{9}$ & 61,9968 & $\mathbf{1 7}$ & 61,9945 & $\mathbf{2 5}$ & 61,9938 & $\mathbf{3 3}$ & 61,9929 \\
\hline $\mathbf{2}$ & 61,9970 & $\mathbf{1 0}$ & 61,9967 & $\mathbf{1 8}$ & 61,9934 & $\mathbf{2 6}$ & 61,9955 & $\mathbf{3 4}$ & 61,9969 \\
\hline $\mathbf{3}$ & 61,9975 & $\mathbf{1 1}$ & 61,9953 & $\mathbf{1 9}$ & 61,9926 & $\mathbf{2 7}$ & 61,9934 & $\mathbf{3 5}$ & 61,9926 \\
\hline $\mathbf{4}$ & 61,9943 & $\mathbf{1 2}$ & 61,9964 & $\mathbf{2 0}$ & 61,9948 & $\mathbf{2 8}$ & 61,9967 & $\mathbf{3 6}$ & 61,9976 \\
\hline $\mathbf{5}$ & 61,9935 & $\mathbf{1 3}$ & 61,9960 & $\mathbf{2 1}$ & 61,9964 & $\mathbf{2 9}$ & 61,9925 & - & - \\
\hline $\mathbf{6}$ & 61,9934 & $\mathbf{1 4}$ & 61,9968 & $\mathbf{2 2}$ & 61,9922 & $\mathbf{3 0}$ & 61,9974 & - & - \\
\hline $\mathbf{7}$ & 61,9976 & $\mathbf{1 5}$ & 61,9957 & $\mathbf{2 3}$ & 61,9957 & $\mathbf{3 1}$ & 61,9963 & - & - \\
\hline $\mathbf{8}$ & 61,9949 & $\mathbf{1 6}$ & 61,9963 & $\mathbf{2 4}$ & 61,9975 & $\mathbf{3 2}$ & 61,9951 & - & - \\
\hline
\end{tabular}

Table 1. Measured values

\section{Verification of the suitability of the measuring equipment}

As mentioned above, we focused on verifying the suitability of the measuring equipment according to a combination of methodologies from Ford and Bosch.

The actual value of the standard must be determined using measuring equipment with an accuracy of an order of magnitude higher. In this case, the nominal value is the calibration ring diameter of $61.997 \mathrm{~mm}$. Based on research in the literature, we concluded that it is not recommended to use a method related to the variance of the process. This is because the variance of the process is often not known, especially for new processes and therefore cannot be used, or because of the change in variance during the process. [9]

Therefore, in this case, we use a calculation related to the field width of the specification $\mathrm{T}$. The determined variance of the measured values is compared with a part of the tolerance field, namely $20 \%$ of the tolerance field. The result is the calculation of the values of the coefficients $\mathrm{Cg}$ and $\mathrm{Cgk}$, for which the Ford relations indicating the repeatability according to the used variant were used. Measuring equipment is considered suitable if $\mathrm{Cg}>1.33$ and $\mathrm{Cgk}>1.33$.

Thanks to the measured values, the capability indices of the measuring equipment were calculated and the minimum width of the tolerance field when the measuring equipment is still suitable was determined. (see table 2)

\begin{tabular}{|c|c|}
\hline \multicolumn{2}{|c|}{ Optical comparator Keyence IM-7000 } \\
\hline Mean measured value: & $61.99533 \mathrm{~mm}$ \\
\hline Calculated standard deviation: & 0.00169 \\
\hline Cg eligibility index: & 1.69206 \\
\hline Cgk eligibility index: & 1.36414 \\
\hline Upper tolerance limit: & $\mathbf{6 2 . 0 4 0 ~} \mathbf{~ m m}$ \\
\hline Lower tolerance limit: & $\mathbf{6 1 . 9 5 4} \mathbf{~ m m}$ \\
\hline Tolerance field width: & $\mathbf{0 , 0 8 6}$ \\
\hline
\end{tabular}

Table 2. Calculated values 


\section{The Conclusion}

The main idea was to determine the minimum width of the tolerance field of the optical comparator Keyence IM7000 , when it still meets the conditions for a capability measuring equipment. The criteria from Ford and Bosch were used to verify the capability, corresponding to the repeatability of the variant used. The gauge is considered suitable if $\mathrm{Cg}>1.33$ and $\mathrm{Cgk}>1.33$. During the measurement, the following was observed:

- the measurements were carried out by one person

- the measurement was performed with one measuring equipment

- the measurement was performed in one way

- the same environmental conditions were ensured during the measurement

- the measurement took place in a relatively short time interval, without a break.

These conditions ensured a minimal effect on the measurement. The constant conditions did not affect the results of measuring. According to the results presented in the previous chapter, the minimum width of the tolerance field of the optical comparator Keyence IM-7000 can be determined. The upper tolerance limit is set at $62.04 \mathrm{~mm}$ and the lower tolerance limit is $61.954 \mathrm{~mm}$. It is therefore possible to say that the optical comparator Keyence IM-7000 has a tolerance field width of $0.086 \mathrm{~mm}$, when it still meets the conditions for a capability of the measuring equipment.

Based on the analysis perfomed, we had verified the capability of the measuring device for the component measurement in the area of automotive, and also in what conditions is this measurement approved. By this step, the effect on the following verification of the process capability was minimized. There is an issue, when the capability is assessed, due to the large amount of input factors. The next aim is to focuse on other factors logically. As a first option, we are going to focuse on the machinery, which is used to produce the components. When focusing only on this machinery, we are also able to perform a reliability study, not only the verification of the capability of the production facilities.

\section{Acknowledgement}

This article was created under the project SGS-2019-008: Research and Development for Innovation in the Field of Manufacturing Technology - Machining Technology III.

\section{References}

[1] Standard for automotive QMS (2016). (Norma pro systém managementu kvality v automobilovém průmyslu) IATF 16949:2016. Praha: ČSJ, 2016

[2] Culka, P. a kolektiv (1996). Management jakosti v automobilovém průmyslu: Zabezpečování jakosti před sériovou výrobou. 2. přeprac. vyd. Praha: Česká společnost pro jakost, 1996. 136 s. ISBN 80-02-01187-2.

[3] Ljungblad, U. (2010): Statistical process control applied to additive manufacturing enables series production of orthopedic implants Annals of DAAAM and Proceedings of the International DAAAM Symposium, pp. 1569-1570. https://www.scopus.com/inward/record.uri?eid=2-s2.084904431140\&partnerID=40\&md5=b1991c7ab3e12a189122e7bc0a9691d0

[4] Bícová, K., a Bebr, L. (2018). Analysis and dependability of production processes for the automotive industry. Paper presented at the Annals of DAAAM and Proceedings of the International DAAAM Symposium, 416-420.

[5] Třeštík, J.(2020): Vyšetřování způsobilosti měřidla "Metoda SPC - Ford" (Examination of the suitability of the meter "SPC method - Ford"). 2020. Cited by: http://www.trestik.cz/msa-spc-ford

[6] Kubátová, D.(2020): Nejistoty měření, studijní materiály (Measurement uncertainties, study materials). UWB Pilsen 2020

[7] Kubátová, Bícová (2020): Contribution to the evaluate the suitability of the measuring equipment. GRANT journal. ISSN 1805-062X, 1805-0638 (online)

[8] Web Keyence (2020). https://www.keyence.eu/landing/measure-sys/pr_im-7000_2_cz.jsp. 2020

[9] Jiroušek, P.(2012): Způsobilost systému měření ve výrobě převodovek ŠKODA AUTO a.s. Diploma thetis, Mladá Boleslav 2012. 